\title{
Algerian Aeronautics Professionals’ Needs Taxonomy: A Target Situation Needs Analysis
}

\author{
Tarek Assassi ${ }^{1}$ \\ ${ }^{1}$ Department of Foreign Languages, Mohamed Khider University of Biskra, Algeria \\ Correspondence: Tarek Assassi, Department of Foreign Languages, Mohamed Khider University of Biskra, \\ Algeria. E-mail: t.assassi@univ-biskra.dz
}

\author{
Received: July 10, $2020 \quad$ Accepted: August 20, $2020 \quad$ Online Published: August 232020 \\ doi:10.5539/ijel.v10n6p90 URL: https://doi.org/10.5539/ijel.v10n6p90
}

\begin{abstract}
This research paper provides a primary thorough needs analysis process for Algerian aeronautics leaners and novice professionals at Aures Aviation Academy. The literature review shed light upon the International Civil Aviation Organization linguistic requirements and the current state of the ESP course at the academy. Accordingly, a hypothesis was set as a tentative answer for two research questions. The process was undertaken via collecting data by administering two questionnaires, two semi-structured interviews and a non-participant classroom observation procedure. The analyzed data were taken into account to answer the research questions through triangulation in data collection methods and sources of information to validate the research outcomes.
\end{abstract}

Keywords: English for specific purposes, aviation English, education, syllabus design, needs analysis

\section{Introduction}

Nowadays, economy is attracting more and more attention, and it is developing in a faster pace. Thanks to smart logistics, most notably air travel, which became a key indicator of a healthy and strong economy. Millions of people and types of merchandise travel daily from and to different parts of the globe. Companies create a competitive atmosphere by providing better services and more importantly, ensure safety and comfort for their clients. On January, 1st, 2008, the International Civil Aviation Organization (ICAO) decreed that all air traffic controllers and air crew members engaged in international flights must show adequate proficiency in general English as a speaking medium and not only limited ICAO radiotelephony phraseology (English is Now the Mandate International Language of Aviation, 2019).

An essential part of the safety measures taken by these companies is ensuring their staff efficient training; most notably pilots' and Air Traffic Controllers' (ATCs') English language communication efficacy. It is clear, so far, that English presents a requirement for integration for any business in today's world, but in aviation it is more than just an asset, it is a very important requirement. In a survey of the United States National Aeronautics and Space Administration (NASA), Aviation Safety Reporting System (ASRS) identifies that more than 90\% of incidents and accidents in aviation are human-related and more than $80 \%$ of them are communication-related, i.e., breakdown of communication. To shed light on the importance of communication in aviation, and in order to be operational on the international airspace; it is mandatory for the cabin crew members, namely pilots, to (1) acquire their flying license, (2) a health certificate, and (3) an English language certificate from an authorized academy or test center.

After the professional training, pilots and air traffic controllers have to sit for an English language test to be eligible for a job at a local or an international company. These tests, such as the RELTA (RMIT English Language Test for Aviation) and the EALTS (English for Aviation Language Testing System), are both approved by the International Civil Aviation Organization. The latter approves tests which comply with its linguistic requirements that are based on the occupational communicative needs.

The current paper presents an initial phase of the general project dedicated to designing a specialized course for aviation professionals (pilots and air traffic controllers) at Aures Aviation Academy in Algeria. This institution provides an intensive training program for the aforementioned learners. The main types of training are as follows: the CPL (Commercial Pilot License), PPL (Private Pilot License) and the highly requested training the ATPL (Airline Transport Pilot License). The ESP course is an essential part of the whole curriculum that consists of 
fourteen specialty subjects taught for a total of nine months in addition to further nine months for practice on simulators, single and twin-engine aircrafts. The ESP teacher relied on a ready-made textbook as the ESP teaching in the academy was not systematic where there was no (1) identification and (2) analysis of learners' linguistic needs to have a clear set of target and learning needs to be (3) used for course design or to adapt the ready-made course. According to Hutchinson and Waters (1987) needs analysis is the pillar for efficient teaching and learning of the English language for specific purposes. Therefore, the identification procedure plays a major role in facilitating the teacher's tasks and enhancing the quality of the teaching/learning experience.

\section{Theoretical Background}

English for Specific Purposes (ESP) is at the crux of this paper. The research focuses on English for Occupational Purposes (EOP) given the nature of the sample under study. Many jobs with international mobility require the use of a lingua franca. After the second world war, and with the openness of the new world through business and new economic horizons, it became apparent that this new globalized community needs a shared means of communication. In the mid-forties, and with the victory of the allies in the second world war, English reached a stronger place to become the lingua franca due to, both, post-war balance of power and the necessity for a common means of communication in the form of language.

That same period, the 1960s, had witnessed the birth of ESP. Specialized classes were highly demanded due to several reasons. First, the fast and steady spread of the English language in Europe and later most of the globe. Second, the openness for more mobility and economic exchange. Finally, businessmen's global pursuit of faster gain; however, learning multiple languages or trusting a group of interprets seemed far reaching. Thus, the need for specific classes which do not require a vast background knowledge and a long duration was in theory a satisfactory mean to an end. Today, ESP has sat on firm ground as "English is now the dominant or official language in over 60 countries ..., and is represented in every continent and in the three major oceans.... It is this spread of representation which makes the application of the term 'world language' a reality" (Crystal, 1995, p. 106).

The role of needs analysis in ESP course design is essential. Hyland (2007) points out that the use of systematic means to define the specific sets of skills, texts, linguistic forms, and communicative practices that a particular group of learners must acquire is central to ESP, informing its curricula and materials and underlining its pragmatic engagement with occupational, academic, and professional realities. Needs analysis is the pillar of course design and a poorly initiated needs analysis will have a negative impact on the next steps of course design from material selection and development to teaching and assessment. Eventually, the intended course will not serve learners' communicative needs as expected and they will not reach the course objectives. Worse still, the impact can reach the target situation as learners will not be able to perform better in their jobs.

\section{Research Method and Data Analysis}

Needs analysis or language needs analysis (LNA), as an integral part of ESP course design, dictates the parameters and the organized steps for the whole process of tailoring an adequate course for ESP learners. According to Dudley-Evan and St John (1998) course design is initiated throughout precise steps, from needs analysis to material selection, teaching/learning and finally evaluation. Precisely, designing the skeleton of the course through sequencing the analyzed data in needs analysis with respect to gradation and frequency of occurrence of linguistic items and skills in the target situation is what helps the designer with the selection of adequate materials.

The researcher aims at shedding light on analyzing the aeronautics professionals' target and learning needs in the Algerian context. The present study seeks to provide a solid base for the expanding project of designing a tentative course for the same sample. It is important to note that target needs might be shared between learners from different linguistic backgrounds. Nevertheless, outcomes are not to be generalized to all professionals who speak other languages. Different studies in ESP needs analysis (in several specific fields) show similarities in target needs, which are 'necessities, lacks and wants', more precisely, necessities and wants. Hutchinson and Waters (1987, p. 53) affirm "what distinguishes ESP from General English is not the existence of a need such as but rather an awareness of the need". This indicates that ESP learners have an acute feeling of their target needs and the linguistic requirements in their fields (Wozniak, 2010). On the other hand, what learners lack linguistically sets out the researcher's contribution, foremost, in designing a successful and reliable course.

The study, then, is based on Hutchinson and Waters' Model of needs analysis. This model is the base for several modern models of ESP course design. The study takes advantage of the diversification of the data collection tools, respondents and different sources of information as supported by Jasso-Aguilar (1999). Thus, a triangulated methodology is opted for in order to collect rich data and provide accurate research outcomes. 
The variety of data sources and respondents helps in avoiding any inaccuracy or dry analysis. In other words, the outcomes in the form of the identified needs will be more reliable and precise as Cowling (2007) denotes "by casting a large net to cover many sources allowed for more opportunities to identify needs and also to filter out any inaccurate perceived needs through the use of triangulation" (p. 429). The study takes into account novice pilots and air traffic controllers (learners) as the primary source of information given the nature of the objective under study. Other respondents that offer important data are the ESP teacher(s), domain professionals (operational pilots and ATCs), specialty teachers and policy makers, which are, in our case administrators. Long (2005) asserts "in LNA, triangulation must involve learners, applied linguists and domain experts" (cited in Wozniak, 2010, p. 244).

To sum up, the main objective of this paper is to identify Algerian pilots' and air traffic controllers' linguistic needs in the target situation. West (1994) corroborates "what learners will be required to do with the foreign language in the target situation, and how learners might best master the target language during this period of training" (p. 1). This indicates that this study takes place during learners' training period since "insiders' perspective is most helpful then" (Wozniak, 2010, p. 243). Which means, respondents provide more accurate information while in-service, these respondents can be learners or similarly, in-service professionals like pilots and air traffic controllers.

For further clarification, Purpura and Graziano-King (2004, p. 4) elaborate

Focusing on the ends constitutes a target language (TL) use situation analysis. This involves the analysis of situations in which the TL will be used. It considers what learners will have to do with the TL outside of the classroom. It is characterized as a description of the characteristics of communication in terms of language contexts, themes, functions, and forms, so that long-range curricular goals can be determined.

After elaborating throughout a thick description of the research process, it is recommended to summarize the main steps for the field work knowing that theory and reality in ESP course design might differ according to the context and the limitations surrounding the research period. The methodological approach is guided by Jordan's ten steps (1997, p. 23) as stated in Wozniak (2010):

The purpose of analysis, delimit student population, decide upon the approach(es), acknowledge constraints/limitations, select methods of collecting data, collect data, analyze and interpret results, determine objectives, implement decisions (i.e., decide upon syllabus, content, materials, methods, etc.), evaluate procedures and results.

The following points state the essential ideas underpinning this study:

- The English language is officially a lingua franca in international aviation operations according to the ICAO.

- The linguistic requirements stated by the ICAO stand as a guide to better understand the communicative necessities for aviation professionals in this research.

- The needs identification and analysis of learners entails a large set of data from different respondents in the domain throughout a triangulated procedure.

- The analyzed needs, most notably target needs are linked to the target communicative context with a closer look at learners' lacks.

The study hypothesizes that if a systematic needs identification and analysis procedure is conducted, it can help unveiling learners' actual lacks, wants and necessities, which eventually leads to a more meaningful learning experience to serve learners' needs. It is also argued that the objective of this paper necessitates a considerable amount of time and energy according to the massive importance of needs analysis in ESP course design. Accordingly, the researcher chose to act as a language specialist rather than a language teacher. The research, in this case, takes all the needed time and focuses on addressing the following questions:

What are the linguistic requirements, both in terms of language aspects and skills, needed by Algerian pilots and ATCs?

- $\quad$ Are the identified needs compatible with the current ESP course taught at the academy? If not, what could it be done?

The following section discusses the data collection procedure and the respondents involved. The question-items and the designed rubrics are based on Hutchinson and Waters (1987) model. 


\subsection{Data Gathering}

The data gathering procedure is based on the triangulation of both sources of data and method. This is opted for to enhance the credibility and reliability of the research outcomes and the validity of the needs analysis process. First, the researcher gathered data from administering a questionnaire to AAA learners and another to subject specialists (specialty instructors and administrators). The next step consisted in designing a semi-structured interview for aviation professionals who were operational at that period. Also, another semi-structured interview of the same nature was designed for the English language teacher (ESP teacher) at the same Academy. It is worth noting that the data collecting tools that the researcher opted for were piloted and modified for a better quality of the acquired responses. Finally, a classroom observation process was undertaken by the researcher as a non-participant observer throughout the educational period of the learners, from January 19th, to February 25th, 2018 , for the total of four sessions.

\subsection{Context of the Study}

Aures Aviation Academy is an Algerian institution specialized in providing training for pilots with different piloting licenses; from a private piloting license to commercial and air transportation piloting license (ATPL), which is the training that the researcher focused on during this study given the sample and training provided at that period; in addition to the significance of this license in comparison to the other types. To become a member of the academy, candidates must hold a baccalaureate degree (secondary school graduate level) in addition to the minimum of two years at a national university (preferably a scientific specialty). Next, a non-fixed financial requirement (fees) must be met by the candidate (depends on the type of training, time and duration), in addition to an interview with a member of the academy who is in charge of pedagogy and enrollment.

The ATPL training offers an opportunity for enrolled candidates to be operational with a national or an international airline company. After a successful enrollment process the learner begins a training that is divided into two phases, each phase takes up to nine months in total. The first phase is dedicated to the theoretical aspect of aviation in which learners sit for thirteen courses (Air Law, Cellule System, Telecommunication, General Aviation Knowledge, Flying Mechanics and Aerodynamics, General Navigation, Radio Navigation, Meteorology, Human Factors, Flight Preparations and Followings, Operational Procedures, IFR and VFR Communication "Instrument and Visual Flight Rules"); in addition to the ESP course. The second phase concerns the practical part. Learners practice piloting skills and apply the learned aspects both on a simulator and a trainer aircraft (single and twin engine aircrafts) with the assistance of the flight instructor.

When learners, i.e., novice pilots finish their training and acquire their certifications, they need two additional certificates so that they can apply for a job at different airline companies. The first assures the physical and mental wellness and the second specifies the English language proficiency of the pilot. The latter is administered by test providers that must be approved by the ICAO. The language tests are based on pre-specified holistic descriptors by the Organization since 2003, as communication efficiency is regarded as a security measure that must be respected at all times to avoid any breakdown in communication that may lead to regrettable incidents and/or tragic accidents.

\subsection{ESP Learners' Questionnaire}

Given the time constraints that this research encountered during the data collection phase, administering a questionnaire seemed very helpful, particularly in terms of dealing with a relatively large sample in a short period of time. As far as the application of this data collection tool, Richards (2005) claims that questionnaires are one of the most common instruments used. They are relatively easy to prepare; they can be used with large numbers of subjects, and they obtain information that is relatively easy to tabulate and analyze (p. 60). Additionally, questionnaires help acquire significant data for needs analysis. Denscombe (2014) limits them into two major points, which are: factual information with unbiased features like age, and attitudes and preferences that hold a personal perspective and personal/biased feedback like in our case the attitude to the ESP course.

This questionnaire is designed for novice aeronautics professionals (learners). The sample comprises twenty novice pilots $(\mathrm{N}=20)$ taking their training at Aures Aviation Academy and five ATCs from the military facility of Reghaia, Algiers where they have their professional training. The questionnaire consists of open and close-ended questions and is divided into four main rubrics which are general questions, learners' linguistic background, their attitude toward the ESP course, and their target needs.

Results

\section{Linguistic Background}

The first rubric of the questionnaire tried to assume as much information as possible on respondents' 
backgrounds, most importantly their linguistic background. First, the researcher noticed the age difference between learners as the training itself does not require a specific age limit and learners must only be over eighteen years of age. The following table shows the age of the respondents.

Table 1. Participants age

\begin{tabular}{lllllll}
\hline Age & 20 & 21 & 22 & 23 & 24 & 25 \\
Frequency & 01 & 01 & 02 & 03 & 02 & 01 \\
\hline Age & 26 & 27 & 29 & 30 & 31 & \\
Frequency & 03 & 04 & 04 & 02 & 02 & \\
\hline
\end{tabular}

As far as the respondents' gender is concerned, most of respondents are males with the frequency of 20 out of 25 , which leaves only two of them to be females. The respondents' view of their English language level was considered mostly as beginners (07) or intermediate (17), with only one respondent who considered their level as advanced. As shown below, the respondents' language background shows no less than six years of educative courses of English as a foreign language. This was an indication of the years they have spent at middle er and secondary school.

Table 2. EFL courses taken by duration

\begin{tabular}{lllllll}
\hline Number of years & 06 & 07 & 08 & 09 & 10 & 11 \\
Frequency & 04 & 06 & 06 & 05 & 02 & 02 \\
\hline
\end{tabular}

The other respondents (17) either took private courses or tutoring and this is shown within the next part. The (17) respondents who took extra courses after secondary school said that they were university courses, ICAO program courses, private courses or TOEFL test training. Six learners reported they took two years at university, which is the minimal educational requirement stated by Aures Aviation Academy, and (03) had four years. Also, (06) stated they took courses at private institutions. The last (02) learners sat for different types of courses, one for the ICAO program, which is more specialized, and the other sat for the TOEFL test preparation course, which is more general English. Within the same rubric, this research tried to explore the exact nature of the course to find out that (08) out of seventeen learners who took extra classes after secondary school sat for general English courses, and one took specialized courses of aviation English, while the rest the respondents (08) sat for a combination of the two. The last question in this rubric addressed learners' attitudes toward the effect of English on their specialized studies in aviation. Unexpectedly (02) learners believed there was no effect whatsoever while (03) were not certain; this shows that these learners are still unaware of the importance of English and its status as an official language in international aviation operations. The remaining (20) respondents answered positively.

The following rubric focused more on the ESP course that they were already taking alongside their professional training. The large majority of learners (23 out of 25$)$ believe that the English is very important. The other respondents (02) labeled it as "important" while no respondent reported that the course was neither not very important or not important at all. As far as the ESP course is concerned, (22) learners stated that it is important to them while (03) said it was not important, which may indicate a negative attitude toward the course but not the subject or the language itself. On the same train of thought, the researcher needed to inquire about the learners' satisfaction with the ESP course content and the following table shows the results.

Table 3. Learners' satisfaction with the ESP course

\begin{tabular}{lllll}
\hline Degree of Satisfaction & $25 \%$ & $50 \%$ & $75 \%$ & $100 \%$ \\
\hline Frequency & 00 & 13 & 09 & 03 \\
\hline
\end{tabular}

As it was explained to the respondents, the learners' satisfaction with the ESP course encompasses the general educational environment in addition to the materials and teaching methods and techniques. Only (03) learners showed their total satisfaction, while (09) of them believed they were $75 \%$ satisfied. The largest number of respondents (13) chose to go for $50 \%$ satisfaction, which may raise the possibility for critical problems in terms of their learning preferences and fulfilling their target and learning needs. 
Classroom participation is a valid indicator for the success of the teaching/learning experience. The importance of observing this phenomenon up-close throughout the observation process is elaborated later in this part. However, perceiving the respondents' perspectives on in-class participation is important for comparative reasons with what it was collected during the observation process. Most of the learners (20) declared that their regular participation during the sessions. While only (05) stated that they do not. In relation to this issue, the researcher included a question related to the difficulties that may be hindering the learners' lack of participation and learning experience in general. The following table discloses:

Table 4. Main difficulties faced by learners in learning English

\begin{tabular}{ll}
\hline Difficulties encountered & Frequency $(25 / 25)$ \\
\hline To write reports & $04 / 25$ \\
To read aviation documents and books & $12 / 20$ \\
To speak with classmates and instructors & $22 / 25$ \\
To listen and understand native speakers talking about aviation & $21 / 25$ \\
\hline
\end{tabular}

The mentioned difficulties present mainly language skills, which are associated with the main tasks that the learners face in simulated situations during their training. Interestingly, this combination is intimately related to the target situation in which these tasks are regularly performed. The answers that respondents provided shifted drastically toward two main skills in association to the specialized tasks, speaking to classmates and instructors (22) and listening to native speakers communicating in aeronautic jargon. This shows the learners awareness of their needs in accordance with the target situation linguistics requirements. As far as reading specialized materials (12) and writing reports (04), the learners' choices reflect the frequency of occurrence of these tasks both inside of the classroom and more significantly within the work environment itself. The following table illustrated the reasons behind such difficulties in the learners' training.

Table 5. Main reasons for the abovementioned difficulties

\begin{tabular}{ll}
\hline Reasons & Difficulties \\
\hline Lack of practice in and outside of the classroom & $24 / 25$ \\
Insufficient period of instruction & $01 / 25$ \\
Lack of reading & $06 / 25$ \\
Lack of interest & $10 / 25$ \\
Other & $02 / 25$ \\
\hline
\end{tabular}

The respondents, in this case, were informed that they can choose more than one option. Lack of practice stood as the main reason of the encountered difficulties with (24) positive response. Lack of interest with (10) responses presented a significant number given the importance of the subject in aviation operations, but at the same time backs up what the researcher mentioned earlier (reported data in Table 3) while reporting data related to learners' interest in the course. Lack of reading was chosen (06) times as one of the reasons that create an instructional disadvantage, while the two responses labeled as (other) dealt mainly with lack of communication as these two learners believed that more communication between all parties involved may enhance the quality of the educational experience. It is possible that this communication is mainly related to the absence of need analysis as some learners may find it demanding to find suitable words and concepts to explain their dismay with the learning experience. Time allocated to the ESP course did not present any issues for the learners, (24) of them were satisfied while only (01) showed disagreement with this point.

The final rubric inquired about the target situation. The highest used source of information for learners vis-à-vis the English language use was the internet as (21) learners rely on materials acquired online mainly for studies. On the other hand, (16) responses were linked to the use of written materials in the form of books (hard cover) and (07) responses for 'interaction' as the main purpose for using the language. Finally, (04) responses for the final option labeled as 'other', in which respondents said that they use English to acquire information that are not quite specialized like chatting and language needed for other tasks like traveling (asking for directions). The main objectives stated by learners are educational like to stay up-to-date with what is new with the global aeronautics community and the linguistic necessity indicated by the ICAO. Other objectives noted were entertainment and random communication.

On the same train of thought, (24) learners specified their choice of being motivated to learn English essentially 
to the obligation and importance given to the language in aviation. Other than that, they were motivated to develop their skills and improve their communicative capacities. The only learner who answered negatively, justified the answer by stating that $\mathrm{s} /$ he does not have the time. In terms of language skills and their importance in the target situation, the following table summarized the respondents' answers.

Table 6. Most important language skills in relation to the target situation

\begin{tabular}{llll}
\hline Language skills classified first most important & Frequency & Language skills classified second most important & Frequency \\
\hline Listening & $17 / 25$ & Speaking & $17 / 25$ \\
Speaking & $02 / 25$ & Listening & $07 / 25$ \\
Reading & $00 / 25$ & Reading & $03 / 25$ \\
Writing & $00 / 25$ & Writing & $03 / 25$ \\
\hline
\end{tabular}

Learners' responses revealed their awareness of the most important language skills in the target situation. This is a sign of a typical ESP learner in general as noted by several scholars like Hutchinson and Waters (1987) and Dudley-Evans and St. John (1998). This also showed that according to the communicative necessities in the target situation, learners were aware of the main tasks that require communication, which is, in most cases, via radiotelephony. Thus, it has been noted that (23) learners were actually aware of the ICAO linguistic requirements but not thoroughly as required, and only two learners had no answers while none of the sample under investigation answered negatively.

It is important, in any need analysis procedure, to pay attention to learners' wants from learning the English language. Typically, learners' necessities and wants can be nearly identical. Learners' responses in our case were not different. As a result of their awareness of the linguistic needs for their future careers, they specified that speaking and listening are what they wanted to learn mostly in addition to well-formed language structure and adequate pronunciation. Learners did not neglect the importance of vocabulary in general and specialized lexical items in particular. Lastly, one of the respondents pointed out to the importance of the target language culture that would help him communicate effectively especially with native speakers.

As final suggestions by the respondents, (06) of them wanted to add extra information. They recommended the use of English on a regular basis. They advised that learning the English language in this case should exceed limited aviation terminology in the form of aviation phraseology. Finally, they pointed out that the importance of English in ensuring flights safety and acquiring new and needed data in their field at all times.

\subsection{Subject Specialists' Questionnaire}

This questionnaire is designed mainly for subject specialists who work at the academy. The list includes eleven $[\mathrm{N}=11]$ respondents as follows:

\section{Instructors}

- $\quad$ Air Law/Operational procedures/ Telecommunication instructor (a former ATC)

- General Knowledge/ "cellule system” instructor (a former pilot)

- Flying mechanics and aerodynamics instructor (military pilot)

- General navigation/Radio navigation instructor (a former ATC)

- Meteorology instructor

- Human factors instructor (a former pilot instructor)

- Cellular system/flight preparations and followings instructor (a former pilot)

\section{Administrators}

- The school's General Manager: He has been working at the academy since its establishment; he is in charge of all of the institution's finances, staff, and recruitments.

- The Training Administrator: he is in charge of the preparation of programs and conducting interviews with interested candidates. He has been with the Academy since 2001.

- Administrator of Installation/Audits are chosen to get more information on English language course and ESP teacher, in addition to the classroom environment and the target situation in relation to the English language learning process of the school in inquiry. 
- The assistant/receptionist is also questioned for the same reasons taking into account her knowledge of the aviation sector and her English language studies (bachelor's degree).

Subject specialists are expected to provide accurate data given their experience both as former aeronautics professionals and instructors. As for administrators, in needs analysis they are more known as policy makers. The importance of their responses mostly concerns the teaching/learning environment, finances, logistics, equipment and the training process.

Throughout this questionnaire, this research deliberately elicited information on the respondents' educational and professional backgrounds, their linguistic background and their current use of English for personal and professional purposes. Furthermore, the questionnaire is developed to acquire more evidence as far as respondents' perspective on collaborating with the ESP teacher and course designer in terms of language needs in the target situation.

\section{Results}

Subject specialists provided important data throughout this questionnaire. Their professional, pedagogical and administrative experiences added crucial perspectives to the already collected data. French is used by the instructors to teach specialized courses since it was the language used during their training and currently as instructors in their teachings and administrators in their correspondences. Furthermore, French is the second most used language in Algeria; as a result, (11) respondents who represent $100 \%$ of the sample/population declared that they use and speak French fluently, while only (04) for English and unexpectedly, (03) for Arabic, even if it is the official national language. As far as the subject specialists' level in English, (09) of them chose 'intermediate' while only one stated that they have a 'beginner' level and one an 'advanced' level.

All the respondents took English language classes. Among the totality of the answers, (09) respondents said that they took both types of courses (English for general purposes and aviation English as a specialized course), and the remaining (02) had only general English courses.

Their answers on their use of the languages professionally were as follows, French is mainly the language that they use for most official paperwork and instruction. The use of English was erratic and in very few technical correspondences. The staff used French and sometimes Arabic (Algerian dialect) in most meetings in or outside of the academy. On the national level, specialized seminars and symposiums did not occur regularly. On the international level, respondents (mainly the teaching staff) testified that they did attend such professional gatherings but they targeted the ones held in French speaking countries. The teaching staff answered the question related to the language used inside of the classroom similarly. All of the (07) teachers reported that they often use the French language and occasionally Arabic in discussions, while English took place only with technical expressions.

As for subject specialists' perspective on using English for instructional purposes, the teachers recognized the importance of using English inside of the classroom given the advantages behind this on both levels (teachers' and learners' practice), yet they asserted that such a decision may take time and effort to apply. On the other hand, administrators recommended the use of the English language particularly in terms of overcoming language use issues such as hesitation and mispronunciation.

The present research sought to acquire data on the subject specialists' viewpoint concerning collaborating with the ESP teacher with view of helping learners master aeronautic English. The respondents showed a positive attitude toward this proposition because of the importance of English in aviation-related operations, but they did not add any specific details on the appropriate method to implement such collaboration. They also indicated their satisfaction with the occurrence of aviation information and the duration of the ESP course, which means that the collaboration process mentioned earlier is still a valid proposal. In relation to the ICAO linguistic requirements, the respondents reported that listening and speaking are the main language skills needed in aviation as radiotelephony is the predominant communication channel in aeronautics. Reading and writing, according to them are also important but to a lesser degree in aviation operations, i.e., the target situation. For final suggestions and recommendations, and given their long experience in aviation, the respondents advocated the role of plain English in the professional life of aeronautics staff. They believed that pilots and air traffic controllers should not focus only on aviation phraseology and technical items as novice aviation professionals will realize that during radiotelephony communication, plain English is as necessary as using phraseology.

\subsection{The Aviation Professionals' Interview}

The importance of thick data in social and human sciences research is mostly assisted by the use of the interview as a data collection tool given its nature of providing rich information on different unknown or slightly 
recognized phenomena. Long (2005) states "Although time consuming, unstructured, or open ended, interviews allow in depth coverage of issues and have the advantage of not preempting unanticipated findings by use of predetermined questions, categories and response options, a potential limitation of structured interviews and questionnaires" (p. 36). In view of that, the use of face to face and semi or unstructured interviews has a considerable advantage as far as the quality of data is concerned. As stated in this section, a face-to-face semi-structured interview was conducted with two operational aviation professionals, a pilot (captain) and an air traffic controller.

The pilot is also a senior instructor at Aures Aviation Academy and the ATC works at Batna International Airport, Algeria. The interview took up to 30 minutes for each respondent. The addition of the open-ended questions is for acquiring specialized data since "in service informants, who often make excellent sources on the content of their job" (Long, 2005, p. 27). The interview tackled mainly the respondents' educational, professional and linguistic background. Also, their perspectives on EGP and ESP courses provided in the country and the use of English in the workplace and outside for other purposes.

\section{Results}

Both aviation professionals are experienced and knowledgeable career-wise. The pilot had his degree in mechanical engineering (cell propulsion) in Algeria before moving to France then Switzerland where he had his training as a pilot. Professionally, and in addition to his long practical training as a captain on several aircrafts, both for Carcassone-Salvaza Airport and Air France companies, he occupied an administrative position in Switzerland (agent piper international) and a maintenance chief as well. The second respondent took two years of science and technology courses at a national university in Algeria, then he had two years of training at a military facility to be certified as an air traffic controller. He had an in-service training at the international airport of Algiers, and now he works at Batna International Airport in Algeria.

Both respondents said that they have an intermediate level in English. They argued that the level they hold is set on a mere occupational ground and for specific work-related necessities. This situation triggered the respondents to add more information on the matter, they believed that this level cannot be sufficient, for instances, in all cases, because English is the official language of aviation. They added that both learners and professionals must have a working knowledge of the language and use it not only on international flights but also on national flights to be familiar with all the situations and, hence, avoid any breakdown of communication.

The aviation professionals were very concise in their answers. Concerning the use of the English language, they stated that it was quite limited, primarily in their jobs. French and Arabic are actually predominantly used while operational. In addition to reading manuals, which occurs on rare occasions, they believe that radiotelephony communication is the main communication channel in their respective jobs. As for other uses of the language, both of them used English on rare instances for online chatting and web searches.

One of the key questions was related to communicative obstacles faced by professionals while operational. Both of them had similar responses. The pilots mentioned issues related to radiotelephony communication with native speakers. He complained about what he perceived as the fast pace of speech and the difficult terminology used in day-to-day English by native speakers, even if it prohibited by the ICAO. He added that it was usually difficult to keep up and sometimes the communication took longer periods of time and stretches of language, which must be avoided at all costs. On the other hand, the ATC, was more persistent on this point given the sensitivity of the subject and the stress and difficulties this causes for ATCs. According to his statement, he believed that such a behavior jeopardizes the safety of the flight particularly when deviating from phraseology that is designed for routine situations to plain English, which is used only on non-routine situations such as incidents and accidents. From an aeronautical safety perspective, he added that this did not cause problems for him yet because he works in a less busy airport but this would not be the case in slightly busier airports.

Both respondents claimed that fluency has become an urgent matter since phraseology does not fulfill all communicative demands in the target situation. As a result, they recommended that both native and non-native speakers should bear mutual responsibility, the former by not opting for plain English as a first choice for routine situations and the latter by being familiarized with more than simply technical English. This is highly required for ensuring flights safety by diminishing the number of human error.

In their answer to the question, which specified their involvement in a critical situation while operational, and if either of them was present in communication-induced breakdown, both candidly answered positively. The pilot admitted that there was a limited number of incidents, none of which was critical. Two of these incidents were due to communication failure, but they were handled successfully without any damage. The main issues were connected to fast pace of speech and unnecessary deviation from phraseology. The ATC mentioned one 
interesting example that he personally encountered where a Turkish Airlines pilot misunderstood the expression "go ahead" provided by the ATC. The latter had to rephrase the sequence for clarification. He used the expression so the pilot could deliver his next message or request, the pilot misunderstood again and moved to the next phase of flight. The ATC claimed that fortunately the airspace was not busy that day, and he took the time he needed to resolve the breakdown of communication.

The pilot suggested the use of English in the practical parts of the training and on national flights, he believed that French might be helpful given the present linguistic situation in Algeria but English is highly required and more advantageous career-wise. Simulation flights and airplane documentation are among the suggestions that the pilot made for novice pilots; also, to use English more especially during their training. The ATC focused on training and the importance of fluency to avoid any breakdown of communication. He believes that some situation-bound communications like medical issues and weather information require much more detailed information and this can be fulfilled through the use of plain English only, thus focusing on this during the training and the ESP course is critical.

\subsection{The ESP Teacher Interview}

The researcher opted for a semi-structured interview that was administered face-to-face with the ESP teacher at Aures Aviation Academy. It tackled the respondents' educational and professional backgrounds to check her experience vis-à-vis ESP course design, and her current teaching experience at the Academy. Furthermore, the researcher took a considerable amount of time to discuss her perspective on learners' lacks, wants and necessities and their compatibility with what is required by the ICAO, in addition to what she provides as materials, content and teaching methods. The researcher did focus also on asking questions about the target situation in ESP. Accordingly, the ESP teacher, if available, can provide a great deal of assistance during the needs analysis process.

\section{Results}

The ESP teacher had an interesting professional experience. After she had earned her bachelors' degree in applied linguistics, she worked as a teacher and an assistant administrator at the Ministry of Finance, in addition to teaching general English in private schools. She had worked for nine years as an ESP teacher at Aures Aviation academy and even if her teaching experience is relatively long (11 years), she had no training as an ESP teacher.

The teacher declared that even, on paper, the ESP course had the same status as other specialty courses, specialty instructors tend to put her course as secondary to the whole course program. She stated that during the nine-month theoretical training period, the learners take general English first using the New Interchange series (1 to 4) divided into eight main units. The learners sit for an achievement test at the end of each unit. Afterwards, learners must achieve all units before they start their specialized English course program using the Macmillan Aviation English materials. The teacher confirmed that no needs analysis procedure was carried out during her teachings. She believed that adopting a ready-made program was easier for her. She chose this course book because she alleged that it contained enough related lessons. Apart from the content and materials used, the teacher claimed that she used the communicative teaching method through the New Interchange series as it helps learners develop their language performance needed for their jobs.

The teacher assumed that learners would prefer to move on directly to aviation English as they do not prefer dull grammar courses. She added that their positive attitude mostly comes from their knowledge of the ICAO linguistic requirement. As a result, she noted that just few learners have a steady development in their learning and most of them do not prefer to practice outside of the classroom. The teacher added that the secondary status of the ESP course and the general English language aspects and skills, in addition to lack of practice stand as impediments toward the main objectives of achieving fluency; and also toward developing plain English, which is highly needed for non-routine situations.

As far as collaborating with specialty instructors, the ESP teacher thought it would be very beneficial for learners. She insisted on the importance of listening and speaking in the target situation and how teaching specialty courses in English, or at least including English may increase the use of these two important skills by learners. The teacher was well aware of the linguistic requirements stated by the ICAO. However, to fulfil the target needs and reach those linguistic requirements is what is challenging in her job. By and large, learners would like to learn how to speak fluently; she explained "they focus more on pronunciation but they neglect informative and comprehensible speech". She summarized learners' lack of vocabulary accuracy and grammatical correctness. Finally, she maintained that the linguistic necessities for the target situation are stated by the ICAO but not clearly enough especially as theory and practice tend to be very different. This is precisely the case of teaching 


\section{English as a foreign language.}

The interview ended with the teacher's suggestions and recommendations. She concluded that collaboration, as the researcher suggested, could be very helpful for learners. Furthermore, she was not apprehensive as far as the teaching content, techniques and duration did not cause any major educational issues. She stated that there was always room for improvement, and that the learners' lacks, particularly in language structure and precise word choice are the two major concerns that need to be addressed.

\subsection{The Classroom Observation Procedure}

It is important to note that observations are one of the most frequently utilized data collection tools especially in case study research (Hancock \& Algozzine, 2006). Unlike interviews, which may transmit controversial biased insights, the observation provides first hand, accurate and objective data for the study. Also, observations can, in some cases, yield data that respondents are unwilling or unable to provide. In ESP, and more precisely in needs analysis, some information cannot be provided by the respondents who in most cases are learners, for a simple reason which is shyness. Yin (1994) asserts that observation is important in studies involving schools and classrooms as the interaction of different individuals cannot be understood without personal observation by the researcher (p. 22). The researcher designed an observation grid that contains different aspects to be observed. The focus is mostly on the teaching method and in-class applied techniques, learners' motivation and attitude toward the course, in addition to the type of language taught and learners' interaction. The observation process lasted for four sessions, two hours each (Sunday to Thursday, from 18:00 to 20:00) and the timing of the class schedule has raised some concerns for the researcher given the busy schedule that the learners had during the day. The researcher was a non-participant observer for the sake of ensuring the naturalness of the context without any distortion that may deteriorate the quality of obtained data.

\section{Results}

The data acquired from the classroom observation were significantly helpful as they came from the natural educational environment, and they are firsthand information. First, the researcher noticed the comfortable, well-equipped, and modern classrooms furnished by the academy. However, the class schedule (18:00-20:00) did not seem to be very helpful to boost the learners' motivation and attitude toward the course. In fact, only the late evening students seemed very interested and that was noticed through their interactions and participation in class activities.

Concerning the teaching approach and techniques adapted by the teacher, the present research witnessed the teaching pattern the teacher used throughout most of the classes by starting with a quick recapitulation of the last session's content by asking questions to refresh the learners' minds. What was also noticed is that the teacher used French on separate occasions to elaborate or to explain vague notions and words. The course or lesson objectives were not mentioned or did communication occur during the session as the researcher noticed the teaching talking time overcoming the learner talking time. This might be caused by learners' attitude toward a specific type of courses mostly those focusing on grammar and structure. What it might be seen as a teacher-centered course cannot be one party's fault, definitely not the teacher's only fault as she needed to cope with the course content and her interaction with a limited number of learners showed her intention, and explained her statement saying that she relied on the communicative teaching method.

The teacher tried to sparingly use the blackboard to give her session a communicative nature. Again, this aloof attitude shown by learners is caused by a number of factors including the class schedule and the nature of the course. The researcher, on many occasions, deduced during the teacher-learners' interactions that the former acts like a resourceful authority rather than a guide or a facilitator; hence, the lingering teacher talking time. The learners did not seem to uphold the initiative to talk or comment, and spoke only when spoken to, and rarely asked for clarification even if in many times they seemed like they did not grasp or understand what had been explained. This is one of the main issues because in aviation talk, asking for information and clarification is considered key to a successful and safe communication. What was noticed also is how learners worked on in-class assignment, most of the work was done individually, the teacher did not encourage the use of pair or group work. It is worth noting that the researcher attended other classes with the same teacher for already operational pilots who took three sessions in order to sit for the official proficiency test, and noticed more interaction. This might be caused by the seriousness of the proficiency test as those who do not succeed cannot be operational. Or, because of the content of the course which dealt with language aspects and skills using specialty-related materials. This group of learners was not a part of the academy learners, thus not a part of the sample under study. The researcher attended these courses to have extra information and learn more about this type of tests and test preparations. 
The teaching materials used by the teacher were largely a part of the course book and she, occasionally, developed her own materials. She presented the exercises and activities in the form of hand-outs. Given the priority of listening and speaking in aviation English, the teacher relied on audiovisual aids to exhibit non-authentic materials like videos and recordings. Finally, the researcher did not witness abundant oral teacher-learners or learner-learner communication. The grammar-based sessions and separating general English from specialized English as the latter was taught only from a purely technical perspective throughout vocabulary can neither serve the educational purposes nor the meeting the ICAO linguistic requirements. Eventually, this will have a negative impact on learners' official proficiency test and most importantly their careers.

\section{Summary of the Main Results}

Needs analysis in ESP course design, as the researcher explained, is a challenging process especially because of the huge gap between theory and practice. The triangulation process in terms of types of data, collection tools and sources on information was very helpful in acquiring rich and supporting data to pinpoint learning needs and more importantly the major target needs.

The target situation, i.e., radiotelephony communication between pilots and air traffic controllers, present a complicated communicative context because of the absence of face-to-face interaction, which makes it difficult for interlocutors to fully grasp or deliver messages. Another reason added to the absence of helping signs such as facial expressions and other forms of paralinguistic features of language, is the limited time allotted to radiotelephony communication, mainly in busy airspaces and non-routine situations. These factors, and many more, make radiotelephony communication via phraseology and plain English an urgent matter due to the vital role of communication in ensuring flight safety.

The importance of foreign language teaching and learning led the present study to explore the understudied area in Algeria and discover more of the training and professional contexts. To sum up this section, this paper discusses different factors affecting the teaching learning context, then the learning needs and finally target needs. First; learners' linguistic background and age shows the significant effect on their language level, it is crucial for any ESP course designer to pay attention to these variables. In fact, the learners have spent different durations learning English, and also, during different periods. This demonstrates the importance of needs analysis and detecting very specific linguistic needs. By collating different respondents' perspectives, this study discovered that most of them realize the importance of English but do not act on it. This was noticed through learners' participation, attitude toward the course, and satisfaction rate with the ESP course as well. The overuse of French cannot be a problem but not incorporating English in specialty courses caused several learning issues both for learners and professionals. Lack of seminars and symposiums in Algeria in addition to Algerian professionals attending the ones held only in French speaking countries led to a certain type of inhibition in terms of developing skills and be up to date in the modern aviation sphere.

As far as the learning needs are concerned, the study detected a number of fundamental issues related primarily to the teaching methods and the class scheduling. The latter presents a serious problem since it has a negative impact on learners' motivation and attitude toward their classes. As for the teaching methods and techniques, adopting two programs (EGP, New Interchange and Macmillan Aviation English) did not seem to be valid and meet learners' needs. The teacher-learner interaction plays a major role in ESP courses and it is highly recommended that learners use language more and for the teacher to help learner do so. Throughout this paper, learners refer to the whole group and not only to high achievers. In aviation operations, interaction is crucial, and helping learners apply this through pair work is exactly what characterizes the target situation.

The present research has noted a consensus amongst all of the respondents concerning the most important language skills in the target situation: listening and speaking accuracy are crucial to a successful radiotelephony communication. However, reading and writing should be focused on as well, but less frequently in the ESP training period because the learners need the two skills in their respective jobs (writing reports and reading manuals) in addition to their importance in the learning process itself. Thus, the course must not overlook any skill; it is just simply a matter of frequency of occurrence in the job, and speaking and listening are consistently necessitated in aviation communication. On the other hand, language aspects are an important part as well, learners showed particular interest in pronunciation. This presents one of the main challenges for learners; the ESP teacher struggled to propose remedial activities to minimize the negative effects of rigid grammar content, but without encouraging results. Consequently, it is better to teach grammar in context and take advantage of the aviation materials to include the vocabulary with which the learners are familiar to avoid boredom. As for vocabulary, the learners preferred technical and semi-technical lexical items and showed disinterest in general vocabulary. This should not be the case because it is considered a handicap, the researcher has noticed that the 
learners strive to provide simple sentences with simple vocabulary. Additionally, non-routine situations such as incidents and accidents in aviation operations require the use of plain English, which is "the spontaneous, creative, and non-coded use of a given language" (ICAO Doc, 9835); this type of language goes beyond strict and limited vocabulary.

Finally, the issue of lack of practice sheds light on several practices that need to be altered toward a straighter lane to fulfilling learners' needs. It is high time the ESP teacher and specialty instructors started collaborating to increase the amount of practice learners go through during their training since they spend a large amount of time inside of the academy (intensive training). The teacher needs to diversify the teaching methods and techniques, and needs to rely more on subject-based and problem-based learning, in which she teaches the language aspects and help practice language skills through contextualized issues and target situation scenarios. Medical and weather topics in aviation are among the subjects that require more practice and the use of problems in the form of incidents and accidents (non-routine situations) can provide a great deal of help for learners to practice interaction and required language functions such as asking for information and clarification in precise words to save time and minimize dramatic incidents.

\section{Conclusion}

In theory, needs analysis is a well-documented and sufficiently researched area in ESP, even if it is still underexplored research especially in social and human sciences. However, in practice, ESP course design, and more specifically needs analysis seems to be still a terra incognita for policy makers and teachers of ESP courses. Many ESP courses around the country still adopt ready-made course books, mostly designed for EGP classes. Even those who adopt specialized course books, do not consider their learners' needs and do not conduct any needs analysis process for several reasons such as lack of equipment, finances and timing.

This paper urges the Algerian aeronautics community to work together with aviation professionals, and show that needs analysis is, indeed, crucial not only to the success of the aeronautic course program but also to the success of their professional career. The Aures Aviation Academy has expressed appreciation for the efforts put into this paper and is willing to reconsider the main points the present study recommended as a result of this investigation. The main linguistic requirements for Algerian pilots and air traffic controllers are summed up into listening and speaking with close attention to comprehensible and well-formed stretches of speech. The functional use of language preserves the quality and accuracy of the communication especially in specific topics such as medical and weather exchanges in aviation. The learners' lacks and necessities that the current syllabus taught at the Academy tries to cover were relatively compatible with the ICAO linguistic requirements but has not fully succeeded to achieve them. Thus, as far as the proposed hypothesis, needs identification and analysis can help unveil the learners' lacks, necessities and wants even in the most organized institutions and fields that do not rely on this process out of sheer ignorance. This last point is proven in this research paper by disclosing different pedagogical issues that were discovered in the already existing ESP course content at the Academy.

\section{References}

Cowling, J. D. (2007). Needs analysis: Planning a syllabus for a series of intensive workplace courses at a leading Japanese company. English for Specific Purposes, 26, 426-442. https://doi.org/10.1016/j.esp.2006.10.003

Crystal, D. (1995). The Cambridge encyclopedia of the English language. Cambridge: Cambridge University Press.

Denscombe, M. (2014). The Good Research Guide: for small-scale social research projects. UK: McGraw-Hill Education.

Dudley-Evans, T., \& St John, M. (1998). Development in English for Specific Purposes: A multi-disciplinary approach. Cambridge: Cambridge University Press.

Hancock, D. R., \& Algozzine, R. (2006). Doing case study research: A practical guide for beginning researchers. New York: Teachers College Press.

Hutchinson, T., \& Waters, A. (7891). English for Specific Purposes: A learning-centered approach. Cambridge: Cambridge University Press.

Hyland, K. (2007). English for Specific Purposes: Some influences and impacts. In J. Cummins \& C. Davison (Eds.), International handbook of English language teaching (pp. 391-402). Norwood, Mass: Springer. https://doi.org/10.1007/978-0-387-46301-8_28

International Civil Aviation Organization (ICAO). (2010). Manual on the implementation of ICAO language 
proficiency requirements (2nd ed., Doc. 9835). Montreal, Canada: ICAO.

Jasso-Aguilar, R. (1999). Sources, Methods and Triangulation in Needs Analysis: A critical perspective in a case study of Waikiki Hotel maids. English for Specific Purposes, 18(1), 27-46. https://doi.org/10.1016/S0889-4906(97)00048-3

Long, M. H. (2005). Methodological Issues in Learner Needs Analysis. In M. H. Long (Ed.), Second language needs analysis (pp. 19-76). Cambridge: Cambridge University Press. https://doi.org/10.1017/CBO9780511667299.002

Purpura, J. E., \& Graziano-King, J. (2004). Investigating the Foreign Language Needs of Professional School Students in International and Public Affairs: A case study. Teachers College, Columbia University Working Papers in TESOL \& Applied Linguistics, 4(1), 1-33.

Richards, J. C. (2005). Communicative Language Teaching Today. SEAMEO Regional Language Centre.

Robson, C. (2008). How to Do a Research Project. Malden, MA: Blackwell Pub.

Wozniak, S. (2010). Language needs analysis from a perspective of international professional mobility: The case of French mountain guides. English for Specific Purposes, 29, 243-252. https://doi.org/10.1016/j.esp.2010.06.001

Yin, R. K. (1994). Case study research: design and methods. Applied Social Research Methods Series, 5. Biography, Sage Publications, London.

English is now the mandate international language of aviation. (2020, February 12). Retrieved from http://www.aviation-esl.com/ICAO_English.htm

\section{Copyrights}

Copyright for this article is retained by the author, with first publication rights granted to the journal.

This is an open-access article distributed under the terms and conditions of the Creative Commons Attribution license (http://creativecommons.org/licenses/by/4.0/). 